\title{
Trolley Dilemma in Papua. Yali horticulturalists refuse to pull the lever
}

\author{
Piotr Sorokowski $^{1} \cdot$ Michalina Marczak $^{1} \cdot$ Michał Misiak $^{1}$ (D) Michał Białek $^{1}$ \\ Published online: 6 January 2020 \\ (C) The Psychonomic Society, Inc. 2020
}

\begin{abstract}
Although many studies show cultural or ecological variability in moral judgments, cross-cultural responses to the trolley problem (kill one person to save five others) indicate that certain moral principles might be prevalent in human populations. We conducted a study in a traditional, indigenous, non-Western society inhabiting the remote Yalimo valley in Papua, Indonesia. We modified the original trolley dilemma to produce an ecologically valid "falling tree dilemma." Our experiment showed that the Yali are significantly less willing than Western people to sacrifice one person to save five others in this moral dilemma. The results indicate that utilitarian moral judgments to the trolley dilemma might be less widespread than previously supposed. On the contrary, they are likely to be mediated by sociocultural factors.
\end{abstract}

Keywords Trolley problem $\cdot$ Moral dilemma $\cdot$ Moral judgment $\cdot$ Moral reasoning $\cdot$ Utilitarianism $\cdot$ Yali

\section{Introduction}

One of the most popular theories in contemporary humanities, social science, and biological science holds that the capability to make moral decisions may be an innate universal human characteristic involving a highly intuitive process of reaching moral verdicts (Greene \& Haidt, 2002; Greene, Sommerville, Nystrom, Darley, \& Cohen, 2001; Haidt, 2001, 2003, 2007). In accord with this view is the concept of a universal "moral grammar" (Mikhail, 2007), analogous to the universal language grammar that Chomsky considered an inborn human feature (Chomsky, 1964). Assumptions about the universal and intuitive foundations of the human moral system are supported by findings in the fields of moral cognition (Hauser et al., 2007; Mikhail, 2007), neuropsychology (Moll et al., 2002; Moll, Eslinger, \& Oliveira-Souza, 2001), evolutionary psychology (Pinker, 1999; Trivers, 1971), and primatology (De Waal, 2013; Flack \& De Waal, 2000). However, evidence for this view of moral judgments remains inconclusive (Awad et al., 2018; Graham et al., 2016; Melnikoff \& Bailey, 2018) and the subject of heated debate.

Piotr Sorokowski

sorokowskipiotr@yahoo.co.uk

1 Institute of Psychology, University of Wroclaw, Wrocław, Poland
Although many studies indicate cultural or ecological variability in moral judgments (Ahlenius \& Tannsjo, 2012; Sadcheva, Singh, \& Medin, 2011; Winskell \& Bhatt, 2019), cross-cultural responses to the "trolley problem" (see below) suggest that certain moral principles may prevail in human populations (Hauser, Cushman, Young, Kang-Xing Jin, \& Mikhail, 2007; O’Neill \& Petrinovich, 1998). We further investigate this issue, focusing our efforts on traditional populations of Yali, in which we believe the nature of moral intuitions most prevails. By contrasting their moral intuitions to industrialized population we strive to show whether there are any critical differences illustrating cultural similarities or differences.

As is commonly done in psychological research (Białek, Turpin, \& Fugelsang, 2019; Bostyn, Sevenhant \& Roets, 2018; Bruers \& Braeckman, 2014; Cathcart, 2013; Edmonds, 2013; Plunkett \& Greene, 2019) in this research we also used a hypothetical moral scenario - the trolley dilemma. The trolley dilemma was first described by Philippa Foot (1967). In the classic version of this thought experiment, a runaway trolley is barreling down a railway track toward five people who are unable to move. The only way to save their lives is to turn a switch to divert the trolley to a different track where, however, one man will be killed. The question underlying the decision to turn the switch in this hypothetical situation is whether it is morally permissible to harm one person to save many people. Most people (89\%, according to Hauser, Young, \& Cushman, 2008) 
agree that it is acceptable to do so, which shows a strong preference for moral utilitarianism: choosing the greatest good for the greatest number (Kahane et al., 2018; Mill, 1863).

Most studies on the trolley problem have not considered the role of culture and have generalized findings from Western populations to other populations (Henrich, Heine, \& Norenzayan, 2010), in line with the moral absolutist view that moral judgments are independent of context or culture. This perspective is supported by the lack of decisive evidence for differences in moral decisions. Specifically, most (of the small number of) cross-cultural studies on the trolley dilemma paradigm found no differences across cultures (Abarbanell \& Hauser, 2010; Gold et al., 2014; Mikhail, 2011; Moore, Lee, Clark, \& Conway, 2011; O’Neill \& Petrinovich, 1998; Winskel \& Bhatt, 2019; but see also: Ahlenius \& Tannsjo, 2012). When found, the differences point out that Easterners (i.e., Chinese in Gold et al., 2014, and Ahlenius \& Tannsjo, 2012; Hindi in Winskel \& Bhatt, 2019) are less likely to act in a utilitarian manner than Westerners (Americans, British, or Russians, who show few cross-cultural differences within this group). ${ }^{1}$

However, these cross-cultural studies have limitations. First, the samples are predominantly small. For example, data in the widely cited Hauser et al.' (2007) study are drawn from only 31 subjects brought up in a non-English-speaking educational system (Brazil) and only 24 subjects from a nonWestern nation (India). Similarly, Gold et al. (2014) tested only 45 Chinese and 55 British individuals. Additionally, the only study of a traditional population (the Maya) used only 30 subjects (Abarbanell \& Hauser, 2010). Second, the background of some samples may render them unrepresentative of the general population. Mikhail's (2011) cross-cultural study was based on data from Chinese immigrants to the USA, the Chinese sample from Moore and colleagues' study (2011) was recruited from students in Hong Kong (British Dependent Territory until 1997), the Hindi sample in Winskel and Bhatt (2019) was recruited from students and staff at an Australian university. Finally, Gold, Colman, and Pulford (2014) collected responses from Chinese students at a British university. Critically, most of the above studies were conducted in English. There is evidence that individuals presented with the trolley dilemma in a language other than their own make distorted decisions: they tend to be less concerned with harm to either the person to be saved or the people to be killed (Białek, Paruzel-Czachura, \& Gawonski, 2019; Hayakawa et al., 2017; Muda, Niszczota, Białek, \& Conway, 2018), and care less for social norms (Białek, Paruzel-Czachura, \& Gawonski, 2019) or motives behind a particular action (Geipel, Hadjichristidis, \& Surian, 2016). It is

\footnotetext{
${ }^{1}$ An interesting finding is that these cultural differences are greater when the consequences are less severe, e.g., financial rather than human lives (Gold et al., 2014; Winskel \& Bhatt, 2019).
}

therefore unclear whether English-language responses to the dilemma from non-English-speaking samples are valid.

Traditionally, moral judgments were understood to be an internal conflict between deontological and utilitarian moral inclinations (Conway \& Gawronski, 2013; Greene, 2015). Most recent advancements on moral cognition, rather than assuming an explicit internal representation of moral philosophy, describes moral judgments as a compromise between social norms, search for best possible consequences, and decision avoidance (Gawronski et al., 2017). Specifically, a person decides whether to act in a moral dilemma after considering intuitions about how they will be perceived in the context of social norms in their society (Bostyn \& Roets, 2017; Everett et al., 2016; Tinghög \& Västfjäll, 2018) and of what will produce the best outcome (Bago \& De Neys, 2018; Białek \& De Neys, 2016, 2017). ${ }^{2}$ Peoples' decision might be classified as deontological despite them holding a utilitarian belief because people tend to opt out from difficult decisions, and non-action is seen as such a solution (Kordes-De Vaal, 1996), or because simply causing harm is aversive enough to overcome people's moral beliefs (Everett et al., 2018). In other words, although people might believe that utilitarian sacrifice is permissible, they are unwilling to make it. People dislike utilitarians and may make deontological decisions as a form of self-presentation, rather than as a reflection of their true moral beliefs (Rom \& Conway, 2018; Reynolds, Knighten, \& Conway, 2019). Lastly, people may also believe that morality does not come from reason, and that one has to obey moral rules, for example, the Ten Commandments for Catholics (Piazza \& Landy, 2013).

Any of these above-listed considerations can cue a moral judgment or decision but does not need to reflect participants' identification with this particular moral philosophy - it may simply reflect other, relevant considerations (Kahane et al., 2015). Of course, all of these considerations stem from culture and lead to the assumption that cultural background and social norms should strongly inform moral judgments. Yet, as we explained above, there is very limited empirical evidence, which additionally suffers some methodological limitations.

To overcome the limitations of previous cross-cultural studies and to provide more data from non-Western traditional populations, we conducted a study in an indigenous Papuan society inhabiting the remote Yalimo valley in Indonesia (see Koch 1974; Marczak et al., 2018), and compared their answers to those of a Western sample. To uphold the ecological validity of the original "trolley" dilemma, we changed it to the "falling tree dilemma."

\footnotetext{
${ }^{2}$ A similar distinction has been proposed by Everett et al. (2018), in which utilitarian decisions stem from impartial care for others (positive utilitarianism, including assessing consequences), and willingness to cause harm to others (negative utilitarianism, including assessing social norms).
} 


\section{Method}

\section{Participants}

We decided to conduct our study among the Yali people of Papua and urban Canadians residing in Alberta, Canada, as these populations are clear examples of non-WEIRD and WEIRD populations (Henrich, Heine, \& Norenzayan, 2010), and because at the time of the study these were the populations we had access to study. We analyzed data obtained from 204 participants: 109 Yali (56 men, mean age 35.98 years, $S D=$ 15.44 , and 53 women, mean age 36.62 years, $S D=13.08$ ) and 95 Canadians (44 men, mean age 33.18 years, $S D=9.90$, and 51 women, mean age 33.24 years, $S D=9.43$ ). The Yali inhabit the Yalimo highlands, east of the Baliem Valley in Papua, a semi-independent province of Indonesia (Zöllner, 1977). Their main means of subsistence is land cultivation, at times supported by hunting and gathering of forest plants (Milliken, 1992). The Yali largely follow a traditional way of life. Their society is polygamous and male-dominated. Men are responsible for hunting, constructing the houses, and participating in warfare, whereas women perform most of the jobs associated with land cultivation and harvesting (Milliken, 1992). The Canadian participants represented a Western industrialized population.

\section{Procedure}

Both the Yali and the Canadian samples were recruited through opportunistic and snowball sampling. All participants provided informed consent before study inclusion and were advised that they could quit the study at any time. The Yali sample provided oral consent owing to high levels of illiteracy in this group. The study procedure complied with the Declaration of Helsinki and received the approval of the authors' institutional ethics committee as well as ethical approval from the head of the local Yali community in West Papua.

To test whether moral judgments in response to the trolley dilemma are universal, we designed a more ecologically valid scenario than the classic trolley problem to take into account the Yali's lack of familiarity with trolleys and railways. The modified scenario features a collapsing tree instead of a barreling trolley. Each participant was asked (with the aid of an interpreter for Yali participants) to decide whether they would push the tree to save five people, making it fall on one person and cause their death, or whether they would do nothing and let the collapsing tree fall on five people, causing their deaths. The following dilemma was read to the participants in their native language:

Imagine you are standing next to a big collapsing tree. The tree is going to fall down. There are five people standing near that tree. There is also another person standing next to the tree, but further away from the group of five people. If you do nothing, the tree will fall directly on the group of five people, causing their deaths. The only way to avoid the deaths of these people is to push the falling tree so that it falls a bit further away, causing the death of the single person.

Is it appropriate for you to push the falling tree to avoid the deaths of the five people?

\section{Results}

The following statistics were performed using $\mathrm{R}$ language for statistical computing (R Core Team 2017) and the 'gmodels' package for R (Warnes, Bolker, Lumley, \& Johnson, 2018). There was a significant association between ethnicity and the decision to push/not push the falling tree $(\chi 2(1)=20.45, p<$ $.001)$. Thirty-seven per cent of Yali compared to $68 \%$ of Canadians decided to push the tree. The odds ratio indicated that the odds of pushing the tree were approximately $73 \%$ smaller for a Papuan in comparison with Canadians (OR= .27 (95\% CI: .14, .5)). The proportion of positive and negative responses to the trolley dilemma across the two studied ethnicities are shown graphically in Fig. 1.

Logistic regression with response to the tree dilemma as dependent variable, ethnicity as explanatory variable, and sex

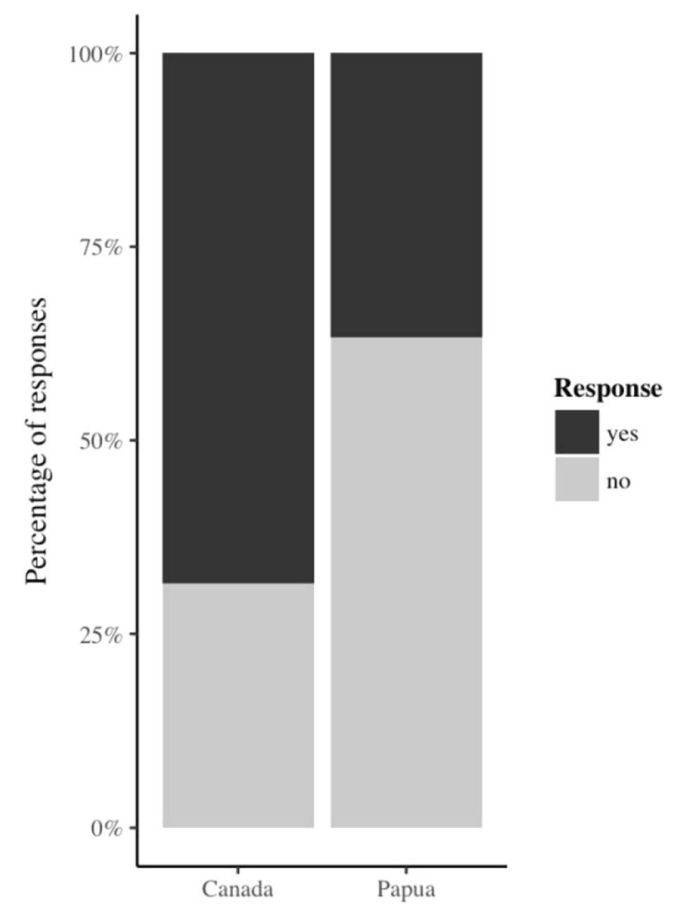

Fig. 1 Proportion of responses to the "trolley" dilemma (" ( ...) is it appropriate for you to push the falling tree to avoid the deaths of the five people?') in Canadians and the Yali 
and age as covariates show that neither sex nor age had a significant effect on people's responses. The results are presented in Table 1.

\section{Discussion}

Our study showed that Yali participants were significantly less willing than Western participants to sacrifice one person to save five others in the moral dilemma. More specifically, the difference was so large that the odds of pushing the tree were approximately $73 \%$ smaller for a Papuan in comparison with Canadians.

Our findings reflect cultural differences between the Western and Yali participants, which are illustrated by the two most common explanations provided by Papuans immediately after the experiment. First, owing to the extremely harsh consequences of causing someone's death in Yali society, our Papuan participants did not want to expose themselves to any potential trouble and were, therefore, unwilling to take any action in the tree dilemma. The rules of conduct in Yali society mean that a person accused of contributing to someone's death is killed. However, the whole extended family of the blamed individual, and even their village, are also in danger of death (Koch, 1974). This is because the relatives of the deceased person are obliged to compensate for the wrongdoing by killing the same or a greater number of persons.

Another common explanation was related to religion. The Yali often argued that people should not interfere with the divine decision about someone's life and death (e.g., "I'm not God, so I can't make the decision"). Hence, although the reason may suggest an action as appropriate, religion suggests otherwise, with religious believers deciding in favor of the latter (Piazza \& Landy, 2013). In turn, more traditional populations may refer to religion more than more secular, modern WEIRD populations. A traditional assumption is that religion is a key determinant of morally relevant behaviors and decisions. However, although findings from experimental studies suggest that religious experience has a direct influence on morally relevant behavior (Bering, 2006; McPhetres,

Table 1 Results of logistic regression with response to the tree dilemma as dependent variable, ethnicity as explanatory variable, and sex and age as covariates

Coefficients

\begin{tabular}{lllll}
\hline & Estimate & Std. Error & $z$ & $p$ \\
\hline (Intercept) & .79 & .64 & 1.23 & 0.22 \\
Ethnicity & -1.32 & .3 .0 & -4.41 & $<0.001$ \\
Age & 0.00 & .01 & .08 & .94 \\
Sex & -.03 & .30 & -.10 & .92 \\
\hline
\end{tabular}

Conway, Hughes, \& Zuckerman, 2018; Piazza \& Landy, 2013; Randolph-Seng \& Nielsen, 2007), many studies in the moral dilemma paradigm report no impact of religious background on participants' moral judgments (Banerjee et al., 2010; Hauser et al., 2007). Moreover, it is difficult to distinguish in practice principles related to religion from other motives, such as normative rules of conduct (Cavanaugh, 2007). Therefore, our findings do not say much about whether identification with moral philosophies is different in Yali and Canadians, but evidences these populations making different moral decisions.

A limitation of our research is that we can't decide about whether social norms affect moral norms per se, or whether they simply affect conventional, prudential rules. Specifically, we don't know whether Yali thought it is immoral to act in the dilemma (because of stronger deontological inclination), or whether they merely thought it is unwise to do so (e.g., because of the chances of revenge from the victim's relatives). One way of thinking about this issue is to consider the CNI Model of moral judgments (Gawronski et al, 2018), in which universal norms have a prominent role in shaping moral judgments. In CNI, moral norms are absolute, logically derived, and specifically not capable of being influenced by culture. These rules are not a coherent set of principles, and they sometimes clash with each other. For example, the rules that conflict in the falling tree dilemma are that one should not cause harm and that one should always intervene to save individuals. We believe that the decision about which rules to care about or which to apply in a particular context might depend on social norms. Both religion and salience of revenge for causing harm (prominent in Yali, but less prominent in lay Canadian society), constitute such social norms and are more salient in Yali population. Therefore, cultural norms cue different responding to moral dilemmas, with Yali producing more deontological decisions than Canadians. Further research is required to attribute these different patterns of responses to a particular cognitive process (i.e., self-presentation, action avoidance, or social status quo). Yet, our findings, in combination with past research, point to different cultures being likely to produce different moral judgments.

Our results indicate that utilitarian moral judgments are probably less widespread than assumed in the literature and that they may be partly mediated by sociocultural factors. From this perspective, our findings highlight the importance of replicating well established psychological phenomena among hard-to-reach traditional populations (Henrich, Heine, \& Norenzayan, 2010).

Data availability statement All data, including statistical analysis scripts, are available on the Open Science Framework (https://osf.io/f8y46/). The study was not preregistered. 


\section{References}

Abarbanell, L., \& Hauser, M. D. (2010). Mayan morality: An exploration of permissible harms. Cognition, 115 (2), 207-224. doi: https://doi. org/10.1016/j.cognition.2009.12.007

Ahlenius, H., \& Tännsjö, T. (2012). Chinese and Westerners respond differently to the trolley dilemmas. Journal of Cognition and Culture, 12(3-4), 195-201.

Awad, E., Dsouza, S., Kim, R., Schulz, J., Henrich, J., Shariff, A., ... \& Rahwan, I. (2018). The Moral Machine experiment. Nature, 563(7729), 59-64.

Bago, B., \& De Neys, W. (2018). The intuitive greater good: Testing the corrective dual process model of moral cognition. Journal of Experimental Psychology: General.

Banerjee K., Huebner B., Hauser M. (2010). Intuitive moral judgments are robust across demographic variation in gender, education, politics, and religion: a large-scale web-based study. Journal of Cognition and Culture, 10(3), 253-281. doi: https://doi.org/10. $1163 / 156853710 X 531186$

Bering, J. M. (2006). The folk psychology of souls. Behavioral and Brain Sciences, 29(5), 453-498. doi: https://doi.org/10.1017/ S0140525X06499106

Białek, M., \& De Neys, W. (2016). Conflict detection during moral decision-making: evidence for deontic reasoners' utilitarian sensitivity. Journal of Cognitive Psychology, 28(5), 631-639.

Białek, M., \& De Neys, W. (2017). Dual processes and moral conflict: Evidence for deontological reasoners' intuitive utilitarian sensitivity. Judgment and Decision Making, 12(2), 148-167.

Białek, M., Turpin, M. H., \& Fugelsang, J. A. (2019). What is the right question for moral psychology to answer? Commentary on Bostyn, Sevenhant, and Roets (2018). Psychological Science, 30(9), 13831385. doi:https://doi.org/10.1177/0956797618815171

Białek, M., Paruzel-Czachura, M., \& Gawronski, B. (2019). Foreign language effects on moral dilemma judgments: An analysis using the CNI model. Journal of Experimental Social Psychology, 85, 103855.

Bostyn, D. H., \& Roets, A. (2017). Trust, trolleys and social dilemmas: A replication study. Journal of Experimental Psychology: General, 146(5), e1-e7. https://doi.org/10.1037/xge0000295

Bostyn, D. H., Sevenhant, S., \& Roets, A. (2018). Of mice, men, and trolleys: Hypothetical judgment versus real-life behavior in trolleystyle moral dilemmas. Psychological Science, 29(7), 1084-1093.

Bruers, S., \& Braeckman, J. (2014). A review and systematization of the trolley problem. Philosophia, 42(2), 251-269. doi: https://doi.org/ 10.1007/s11406-013-9507-5

Cathcart, T. (2013). The Trolley Problem, Or Would You Throw the Fat Man Off the Bridge? A Philosophical Conundrum. New York: Workman Publishing.

Cavanaugh, W. (2007). Does Religion Cause Violence? Harvard Divinity Bulletin, 35 (2-3), 1-16.

Chomsky, N. (1964), Current Issues in Linguistic Theory. The Hague: Mouton

Conway, P., \& Gawronski, B. (2013). Deontological and utilitarian inclinations in moral decision making: a process dissociation approach. Journal of Personality and Social Psychology, 104(2), 216-235.

De Waal, F. (2013). The bonobo and the atheist: In search of humanism among the primates. New York: WW Norton \& Company.

Edmonds, D. (2013). Would you kill the fat man?: The trolley problem and what your answer tells us about right and wrong: Princeton University Press.

Everett, J. A., Faber, N. S., Savulescu, J., \& Crockett, M. J. (2018). The costs of being consequentialist: Social inference from instrumental harm and impartial beneficence. Journal of experimental social psychology, 79, 200-216.
Everett, J. A., Pizarro, D. A., \& Crockett, M. J. (2016). Inference of trustworthiness from intuitive moral judgments. Journal of Experimental Psychology: General, 145(6), 772-787.

Flack, J. C., \& De Waal, F. (2000). 'Any animal whatever'. Darwinian building blocks of morality in monkeys and apes. Journal of Consciousness Studies, 7(1-2), 1-29.

Foot, P. (1967). The problem of abortion and the doctrine of double effect. Oxford Review, 5.

Gawronski, B., Armstrong, J., Conway, P., Friesdorf, R., \& Hütter, M. (2017). Consequences, norms, and generalized inaction in moral dilemmas: The CNI model of moral decision-making. Journal of Personality and Social Psychology, 113(3), 343.

Geipel, J., Hadjichristidis, C., \& Surian, L. (2016). Foreign language affects the contribution of intentions and outcomes to moral judgment. Cognition, 154, 34-39.

Gold, N., Colman, A. M., \& Pulford, B. D. (2014). Cultural differences in responses to real-life and hypothetical trolley problems. Judgment and Decision Making, 9(1), 65-76.

Graham, J., Meindl, P., Beall, E., Johnson, K. M., \& Zhang, L. (2016). Cultural differences in moral judgment and behavior, across and within societies. Current Opinion in Psychology, 8, 125-130. doi: https://doi.org/10.1016/j.copsyc.2015.09.007

Greene, J. D. (2015). The rise of moral cognition. Cognition, 135, 39-42.

Greene, J., \& Haidt, J. (2002). How (and where) does moral judgment work? Trends in Cognitive Sciences, 6(12), 517-523. doi: https://doi org/10.1016/S1364-6613(02)02011-9

Greene, J. D., Sommerville, R. B., Nystrom, L. E., Darley, J. M., \& Cohen, J. D. (2001). An fMRI investigation of emotional engagement in moral judgment. Science, 293(5537), 2105-2108.

Haidt, J. (2001). The emotional dog and its rational tail: a social intuitionist approach to moral judgment. Psychological Review, 108(4), 814834.

Haidt, J. (2003). The moral emotions. In R. J. Davidson, K. R. Scherer, \& H. H. Goldsmith (Eds.), Handbook of affective sciences (pp. 852870). Oxford: Oxford University Press.

Hauser, M., Cushman, F., Young, L., Kang-Xing Jin, R., \& Mikhail, J. (2007). A dissociation between moral judgments and justifications. Mind \& Language, 22(1), 1-21. doi: https://doi.org/10.1111/j.14680017.2006.00297.x

Hauser, M., Young, L., \& Cushman, F. (2008). Reviving Rawls' Linguistic Analogy: Operative principles and the causal structure of moral actions. In W. Sinnott-Armstrong (Ed.), Moral psychology and biology. New York: Oxford University Press.

Hayakawa, S., Tannenbaum, D., Costa, A., Corey, J. D., \& Keysar, B. (2017). Thinking more or feeling less? Explaining the foreignlanguage effect on moral judgment. Psychological science, 28(10), $1387-1397$

Henrich, J., Heine, S. J., \& Norenzayan, A. (2010). The weirdest people in the world? Behavioral and Brain Sciences, 33(2-3), 61-83. doi: https://doi.org/10.1017/S0140525X0999152X

Kahane, G., Everett, J. A. C., Earp, B. D., Caviola, L., Faber, N. S., Crockett, M. J., \& Savulescu, J. (2018). Beyond sacrificial harm: A two-dimensional model of utilitarian psychology. Psychological Review, 125(2), 131-164. https://doi.org/10.1037/rev0000093

Kahane, G., Everett, J. A., Earp, B. D., Farias, M., \& Savulescu, J. (2015). 'Utilitarian'judgments in sacrificial moral dilemmas do not reflect impartial concern for the greater good. Cognition, 134, 193-209.

Koch, K. F. (1974). War and peace in Jalemo: The management of conflict in Highland New Guinea. Harvard University Press.

Kordes-de Vaal, J. H. (1996). Intention and the omission bias: Omissions perceived as nondecisions. Acta Psychologica, 93(1-3), 161-172.

Marczak, M., Misiak, M., Sorokowska, A., \& Sorokowski, P. (2018). No sex difference in digit ratios (2D: 4D) in the traditional Yali of Papua and its meaning for the previous hypotheses on the interpopulational variability in 2D:4D. American Journal of Human Biology, 30(2), e23078. doi: https://doi.org/10.1002/ajhb.23078 
McPhetres, J., Conway, P., Hughes, J. S., \& Zuckerman, M. (2018). Reflecting on God's will: Reflective processing contributes to religious peoples' deontological dilemma responses. Journal of Experimental Social Psychology, 79, 301-314.

Melnikoff, D. E., \& Bailey, A. H. (2018). Preferences for moral vs. immoral traits in others are conditional. Proceedings of the National Academy of Sciences, 201714945. doi: https://doi.org/10.1073/pnas. 1714945115

Mikhail, J. (2007). Universal moral grammar: Theory, evidence and the future. Trends in Cognitive Sciences, 11(4), 143-152. doi: https://doi. org/10.1016/j.tics.2006.12.007

Mikhail, J. (2011). Elements of moral cognition: Rawls' linguistic analogy and the cognitive science of moral and legal judgment. Cambridge University Press.

Mill, J. S. (1863). Utilitarianism. London: Parker, Son, and Bourn.

Milliken, W. (1992). Ethnobotany of the Yali of West Papua. Edinburgh: Royal Botanic Garden, 7, 19.

Moll, J., de Oliveira-Souza, R., Eslinger, P. J., Bramati, I. E., MourãoMiranda, J. n., Andreiuolo, P. A., \& Pessoa, L. (2002). The neural correlates of moral sensitivity: a functional magnetic resonance imaging investigation of basic and moral emotions. Journal of Neuroscience, 22(7), 2730-2736. doi: https://doi.org/10.1523/ JNEUROSCI.22-07-02730.2002

Moll, J., Eslinger, P. J., \& Oliveira-Souza, R. d. (2001). Frontopolar and anterior temporal cortex activation in a moral judgment task: preliminary functional MRI results in normal subjects. Arquivos de Neuro-Psiquiatria, 59(3B), 657-664. doi: https://doi.org/10.1590/ S0004-282X2001000500001

Moore, A. B., Lee, N. L., Clark, B. A., \& Conway, A. R. (2011). In defense of the personal/impersonal distinction in moral psychology research: Cross-cultural validation of the dual process model of moral judgment. Judgment and Decision Making, 6(3), 186-195.

Muda, R., Niszczota, P., Białek, M., \& Conway, P. (2018). Reading dilemmas in a foreign language reduces both deontological and utilitarian response tendencies. Journal of Experimental Psychology: Learning, Memory, and Cognition, 44(2), 321.

O’Neill, P., \& Petrinovich, L. (1998). A preliminary cross-cultural study of moral intuitions. Evolution and Human Behavior, 19(6), 349-367. doi: https://doi.org/10.1016/S1090-5138(98)00030-0

Piazza, J., \& Landy, J. (2013). "Lean not on your own understanding": belief that morality is founded on divine authority and non-utilitarian moral thinking. Judgment and Decision Making, 8(6), 639-661.
Pinker, S. (1999). How the mind works. Annals of the New York Academy of Sciences, 882(1), 119-127. doi: https://doi.org/10.1111/j.17496632.1999.tb08538.x

Plunkett, D., \& Greene, J. D. (2019). Overlooked evidence and a misunderstanding of what trolley dilemmas do best: Commentary on Bostyn, Sevenhant, and Roets (2018). Psychological science, 30(9), 1389-1391. doi:https://doi.org/10.1177/0956797619827914

R Core Team (2017). R: A language and environment for statistical computing. R Foundation for Statistical Computing, Vienna, Austria. URL https://www.R-project.org/.

Randolph-Seng, B., \& Nielsen, M. E. (2007). Honesty: One effect of primed religious representations. The International Journal for the Psychology of Religion, 17(4), 303-315. doi: https://doi.org/10. 1080/10508610701572812

Reynolds, C. J., Knighten, K. R., \& Conway, P. (2019). Mirror, mirror, on the wall, who is deontological? Completing moral dilemmas in front of mirrors increases deontological but not utilitarian response tendencies. Cognition, 192, 103993.

Rom, S. C., \& Conway, P. (2018). The strategic moral self: Selfpresentation shapes moral dilemma judgments. Journal of Experimental Social Psychology, 74, 24-37.

Sachdeva, S., Singh, P., \& Medin, D. (2011). Culture and the quest for universal principles in moral reasoning. International Journal of Psychology, 46(3), 161-176.

Tinghög, G., \& Västfjäll, D. (2018). Why people hate health economics Two psychological explanations (LiU Working Papers in Economics, No. 6). Linköping, Sweden: Division of Economics, Department of Management and Engineering, Linköping University.

Trivers, R. L. (1971). The evolution of reciprocal altruism. The Quarterly Review of Biology, 46(1), 35-57.

Warnes, G. R., Bolker, B. Lumley, T., \& Johnson, R. C. (2018). Package 'gmodels'. URL https://cran.r-project.org/web/packages/gmodels/ index.html

Winskel, H., \& Bhatt, D. (2019). The role of culture and language in moral decision-making. Culture and Brain, 1-19.

Zöllner, S. (1977). Lebensbaum und Schweinekult: Die Religion der Jalî im Bergland von Irian-Jaya (West-Neu-Guinea). Brockhaus.

Publisher's note Springer Nature remains neutral with regard to jurisdictional claims in published maps and institutional affiliations. 